\title{
Emergency Cerclage Placement in Multifetal Pregnancies with a Dilated Cervix and Exposed Membranes: Case Series
}

\author{
Marijo Aguilera, MD ${ }^{1}$ Kirk Ramin, $\mathrm{MD}^{2}$ Ruby Nguyen, $\mathrm{PhD}^{3}$ Lauren Giacobbe, MD ${ }^{2}$ \\ Jessica Swartout, MD ${ }^{1}$
}

${ }^{1}$ Minnesota Perinatal Physicians, Abbott Northwestern Hospital, Minneapolis, Minnesota

2 Division of Maternal-Fetal Medicine, Department of Obstetrics and Gynecology, University of Minnesota, Minneapolis, Minnesota

${ }^{3}$ Department of Epidemiology and Community Health, School of

Public Health, University of Minnesota, Minneapolis, Minnesota

\begin{abstract}
Address for correspondence Marijo N Aguilera, MD, Piper Building, Suite 503, 800 East 28th Street, Minneapolis, MN 55407

(e-mail: mnaguilera5@hotmail.com).
\end{abstract}

Am J Perinatol Rep 2013;3:1-4.

\begin{abstract}
Pregnancies complicated by midtrimester painless cervical dilation are known to have associations with preterm birth. In situations where fetal amniotic membranes are exposed, the risk of perinatal morbidity and mortality increases dramatically in this particularly high-risk population. Multifetal gestations further increase the risk of

Keywords

- emergency cerclage

- cervical insufficiency

- twin pregnancy

- exposed fetal membranes preterm birth, yet there remains a paucity of data supporting therapeutic intervention for these patients. We report a case series of 12 multifetal gestations with painless cervical dilation and exposed fetal membranes that underwent emergency cerclage placement. Pregnancy prolongation was achieved on average 60.25 days with $76.9 \%$ neonatal survival. These findings are suggestive that emergency cerclage may be a beneficial treatment in this unique patient population.
\end{abstract}

Multifetal gestations comprise 3\% of all births in the United States, with nearly $60 \%$ of twin pregnancies and greater than $90 \%$ of triplets delivering preterm. ${ }^{1}$ Despite the disproportionate contribution to perinatal morbidity and mortality, an effective prevention strategy for preterm delivery has yet to be discovered. Cervical insufficiency, defined as painless second-trimester cervical dilatation, is a well-recognized etiology of preterm birth. Identifying cervical shortening on obstetric sonography suggests the diagnosis of cervical insufficiency, and multiple studies have shown that decreased cervical length is directly associated with an increase in preterm birth in both twin and triplet pregnancies. ${ }^{2-7}$ In women with a history of a prior preterm birth or those at increased risk for preterm delivery based on gynecologic risk factors, placement of a cerclage has been shown to reduce the incidence of preterm delivery in singleton gestations when cervical shortening is identified. ${ }^{8,9}$ Cerclage placement

received

March 19, 2012

accepted after revision

May 16, 2012

published online

October 24, 2012 following cervical shortening in twin or triplet gestations has not been shown to significantly decrease preterm birth or to reduce neonatal morbidity and has even been associated with an increase in preterm birth on systematic reviews. ${ }^{10-12}$ Nonetheless, cervical dilation with fetal amniotic membrane exposure above or below the level of the external cervical os increases the risk of extreme preterm delivery and chorioamnionitis. Though delivery may not be imminent, the overall rate of preterm birth in these pregnancies has been reported as high as $90 \%{ }^{13-18}$ There are now multiple trials evaluating emergency cerclage placement in women with second-trimester cervical dilatation, and the available data suggest that cerclage may play an important role in prolonging pregnancy and thus improve perinatal outcome. ${ }^{13-18}$

Whereas data from these studies are promising, there remains a paucity of data addressing the utility of emergency cerclage placement in multifetal gestations. Herein, we
Copyright ( 2013 by Thieme Medical Publishers, Inc., 333 Seventh Avenue, New York, NY 10001, USA. Tel: +1(212) 584-4662.
DOI http://dx.doi.org/ 10.1055/s-0032-1326995. ISSN 2157-6998. 
document the length of pregnancy prolongation achieved following emergency cerclage placement in a series of 12 multifetal gestations with preterm cervical dilatation and exposed fetal amniotic membranes prior to 24 weeks.

\section{Materials and Methods}

Patients were identified by a query of all cerclage placements performed by the maternal-fetal medicine service at Abbott Northwestern Hospital (ANW) in Minneapolis, Minnesota, between January 2008 and February 2011. ANW is a tertiary care center receiving maternal transports from Minnesota, North and South Dakota, and Wisconsin. The 3-year time period was chosen based on the initiation of standard protocols in managing rescue cerclage placement during that time. Consistent with these protocols, cerclage placement was performed if: (1) there were no regular painful uterine contractions present, (2) fetal amniotic membranes were intact, (3) there was no significant bleeding present, (4) there were no obvious signs or symptoms of intra-amniotic infection, and (5) there were no known fetal anomalies or aneuploidy. Amniocentesis to assess for intrauterine infection was not routinely performed, but rather a clinical diagnosis of chorioamnionitis was utilized based on maternal uterine tenderness, a temperature of $38^{\circ} \mathrm{C}$ or greater, significant leukocytosis, or maternal tachycardia. Patients were excluded from cerclage placement if they had preterm premature rupture of membranes, significant vaginal bleeding, persistent regular uterine contractions, suspected chorioamnionitis, known fetal anomalies, or known aneuploidy.

Patients in this series were identified as candidates for an emergency cerclage by either of the following methods: (1) they were found to have a shortened cervix on routine cervical length surveillance ultrasound or (2) they presented to their primary physician with subjective complaints of increased pelvic pressure or vaginal discharge and then underwent cervical length sonography. All patients subsequently underwent speculum exam after cervical length ultrasound examination to identify cervical dilatation with exposed fetal membranes. Patients in whom the membranes were easily visualized through a dilated internal cervical os were included in the analysis.

A McDonald-type rescue cerclage was placed in all cases, and distention of the urinary bladder and/or a Foley balloon was used when necessary to replace the fetal membranes into the uterine cavity. All patients were admitted preoperatively and evaluated for the previously described exclusion criteria. During this evaluation, they received perioperative indomethacin or ketorolac and piperacillin/tazobactam for a period of between 6 and 24 hours prior to cerclage placement. After the surgical procedure, patients were continued on the indomethacin or ketorolac and piperacillin/tazobactam and were observed on an inpatient basis in the antepartum unit until discharge 48 to 72 hours postoperatively. Minimal to absent uterine activity was confirmed prior to discharge. Patients were instructed to maintain home bed rest and to follow up for cervical length sonographic assessment 7 to 14 days after discharge. The remaining clinical management, including readmission for observation, tocolysis, and level of activity, was made on an individual patient basis.

Our primary outcome of interest was time from cerclage placement to delivery (pregnancy prolongation). We calculated the cumulative proportion pregnant using the KaplanMeier method; two women who were lost due to attrition contributed data from the time of cerclage until they were censored. Secondary outcomes we recorded were gestational age at delivery, twin infants' weight at delivery, Apgar scores, and neonatal survival. STATA v.12 (College Park, TX) was used for the Kaplan-Meier estimates and graph.

\section{Results}

We identified 15 multifetal gestations that underwent emergency cerclage in the 3-year period including 13 twin gestations and two triplet gestations. All patients included in the analysis had visible fetal membranes through a dilated internal cervical os on speculum exam. One patient was excluded due to indicated preterm delivery for severe preeclampsia. Additionally, delivery information was unavailable for two gestations due to attrition of the mothers from our clinic, leaving 12 total pregnancies for the pregnancy outcome analysis ( 10 twins and two triplet gestations). The average maternal age was $27.8 \pm 7$ years (range 17 to 39 years). Eleven of the patients (91.7\%) were nulliparous (eight patients were primigravidas and three patients had a history of a first-trimester spontaneous abortion), and one patient had a history of a prior term delivery. None of the patients had a history of a prior preterm delivery or second-trimester loss. One patient had a history of a prior loop electrosurgical excision procedure; no other patients had gynecologic risk factors for cervical insufficiency including müllerian anomalies. Only one patient presented with symptoms of increased vaginal discharge; the remaining 11 patients were noted to have cervical shortening or dilation on ultrasound with subsequent dilation and visible fetal amniotic membranes documented on speculum exam.

All 12 McDonald rescue cerclages were successfully placed. Membrane rupture did not occur in any of the cases, and there were no other operative complications. The mean gestational age at the time of cerclage placement was $20.6 \pm 2.6$ weeks (range 14.9 to 23.7 weeks). Mean cervical dilatation was $1.8 \pm 0.9 \mathrm{~cm}$ (range 0.5 to $3 \mathrm{~cm}$ ), and two patients (16.7\%) had amniotic membranes prolapsing through the external cervical os into the vagina. See - Table 1 for study group characteristics of patients included in analysis.

Of the two twin gestations without delivery information, cerclage placement occurred at 22.3 and 21.7 weeks. The gestational age at last documented follow-up was 29 and 33 weeks, respectively (pregnancy prolongation of at least 47 and 79 days). These two patients contributed data to the Kaplan-Meier survival graph. One additional patient was excluded in the analysis due to an indicated preterm delivery at 24.3 weeks secondary to severe preeclampsia and abnormal umbilical artery Doppler studies. Her cerclage had been placed at 20.1 weeks' gestation, thus her pregnancy was prolonged by 29 days prior to delivery. Twin A weighed $520 \mathrm{~g}$ and twin B weighed $480 \mathrm{~g}$; both twins survived. 
Table 1 Patient characteristics of pregnancies included in analysis

\begin{tabular}{|l|l|l|l|}
\hline Characteristic & $\begin{array}{l}\text { All patients } \\
(\boldsymbol{n}=12)\end{array}$ & $\begin{array}{l}\text { Twin gestations } \\
(\boldsymbol{n}=10)\end{array}$ & $\begin{array}{l}\text { Triplet gestations } \\
(\boldsymbol{n}=\mathbf{2})\end{array}$ \\
\hline Age $(\mathrm{y})$ & $27.8( \pm 7)$ & $27.6( \pm 7.4)$ & $32.5( \pm 3.5)$ \\
\hline Smoking $(n)$ & 2 & 2 & 0 \\
\hline Gynecologic risk factors $(n)$ & 1 & 0 & 1 \\
\hline Prior preterm delivery $(n)$ & 0 & 0 & 0 \\
\hline Gestational age at cerclage (wk) & $20.6( \pm 2.6)$ & $20.6( \pm 2.5)$ & $20.5( \pm 4.5)$ \\
\hline Cervical dilatation $(c m)$ at cerclage & $1.8( \pm 0.9)$ & $1.9( \pm 0.9)$ & 1 \\
\hline Membrane exposure at or above the external os $(n)$ & 10 & 8 & 2 \\
\hline Membrane exposure beyond the external os $(n)$ & 2 & 2 & 0 \\
\hline
\end{tabular}

The mean latency period from cerclage placement to delivery was $60.25 \pm 30.82$ days (range 4 to 102 days) with a mean gestational age at delivery of $29.2 \pm 5.5$ weeks (range 20.3 to 38.3 weeks). Overall, the mean birth weight was $1572 \pm 415 \mathrm{~g}$, and mean Apgar scores at 1 and 5 minutes were $7 \pm 2.1$ and $8.3 \pm 1.3$, respectively. Results of patients with known delivery information are displayed in - Table 2. Cumulative proportion pregnant after emergency cerclage placement is expressed in the Kaplan-Meier graph in - Fig. 1. Fourteen patients are represented (excluding only the one patient who underwent indicated delivery), and the two patients lost to attrition are censored.

Eight patients (61.5\%) delivered at $\geq 30$ weeks' gestation, $4(30.8 \%)$ at $\geq 32$ weeks, and one delivered at term. Three patients (23\%) delivered before 24 weeks' gestation, and the neonates did not survive. Of these nonviable deliveries, two of the women (67\%) had presented with amniotic membranes prolapsing through the external cervical os, and the third patient had a cervical dilation of $0.5 \mathrm{~cm}$ with amniotic membranes visible at the level of the external os. Histological chorioamnionitis was present in all three of these cases. The only multiparous patient with a history of a prior term delivery delivered at 30.3 weeks following spontaneous preterm labor.

\section{Discussion}

Painless second-trimester cervical dilatation with exposed fetal amniotic membranes is an extremely high-risk clinical picture that is a known contributor to spontaneous preterm birth (SPTB) and resultant perinatal morbidity and mortality.

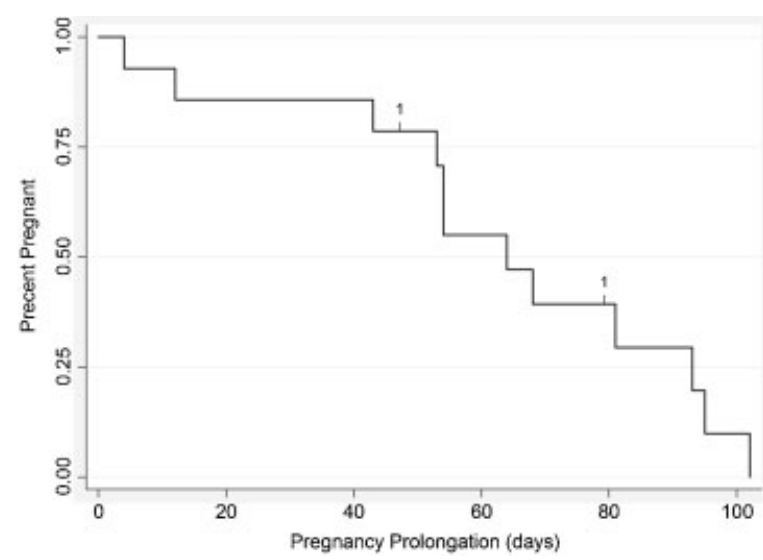

Fig. 1 Kaplan-Meier curve of the cumulative proportion pregnant after emergency cerclage in 14 multifetal pregnancies. ${ }^{*}$ Hash lines on the Kaplan-Meier curve indicate the two patients censored due to attrition at 47 and 79 days.

Multifetal gestations are at a heightened risk of preterm delivery, and despite years of research aimed at preventing SPTB, the incidence among these women remains unchanged. ${ }^{1}$

Use of cervical length sonography to detect cervical shortening has become a common method of surveillance. The association with cervical shortening and SPTB in multifetal pregnancies has been established through multiple trials, with the risk of SPTB inversely proportionate to cervical length. ${ }^{2-7}$ Despite these associations, trials investigating the utility of cerclage placement in multifetal pregnancies identified with cervical shortening on ultrasound have not shown a benefit. 8,9

Table 2 Pregnancy outcomes on patients with known delivery information

\begin{tabular}{|l|l|l|l|}
\hline Outcome & All patients $(\boldsymbol{n}=12)$ & Twin gestations $(\boldsymbol{n}=10)$ & Triplet gestations $(\boldsymbol{n}=\mathbf{2})$ \\
\hline Pregnancy prolongation $(\mathrm{d})$ & $60.25( \pm 30.82)$ & $56.4( \pm 31.76)$ & $79.5( \pm 21.92)$ \\
\hline Gestational age at delivery $(\mathrm{wk})$ & $29.2( \pm 5.5)$ & $28.7( \pm 5.9)$ & $31.9( \pm 1.4)$ \\
\hline Live births $(n)$ & $20 / 26(76.9 \%)$ & $14 / 20(70 \%)$ & $6 / 6(100 \%)$ \\
\hline Birth weight $(\mathrm{g})$ & $1572( \pm 415)$ & $1542( \pm 113)$ & $1646( \pm 187)$ \\
\hline Neonatal survival $(\mathrm{n})$ & $20 / 26(76.9 \%)$ & $14 / 20(70 \%)$ & $6 / 6(100 \%)$ \\
\hline Apgar score $(1 \mathrm{~min})$ & $7( \pm 2.1)$ & $7( \pm 2.1)$ & $8( \pm 0.6)$ \\
\hline Apgar score $(5 \mathrm{~min})$ & $8.3( \pm 1.3)$ & $8.4( \pm 2.9)$ & $9( \pm 0)$ \\
\hline
\end{tabular}


In our series, we found that emergency cerclage placement is associated with a pregnancy prolongation of $\sim 60.25$ days and a presumed paralleled benefit of increased neonatal survival and higher birth weight. These observations are consistent with multiple retrospective studies evaluating singleton gestations that have demonstrated a significant reduction in SPTB and improved neonatal survival in women who underwent emergency cerclage versus bed rest in light of preterm cervical dilatation and exposed/prolapsing membranes. ${ }^{13-18}$ However, studies including multifetal gestations are surprisingly limited. A separate analysis from the Cervical Incompetence Prevention Randomized Cerclage Trial (CIPRACT) by Althuisius et al included seven twin gestations (three received cerclage and four were allocated to bed rest); however, they were not analyzed separately. ${ }^{13}$ Gupta and colleagues investigated emergency cerclage in their trial that included 11 twin pregnancies. A "good outcome," in which the pregnancy reached 32 weeks with a healthy neonate, was achieved in $36.4 \%$ of twin gestations. ${ }^{14}$

It is clear from the existing data that more information is necessary to assist in the management of multifetal gestations with cervical insufficiency. Whereas the data investigating cerclage placement for the indication of cervical shortening on ultrasound does not suggest a benefit, and even possibly a detrimental effect, the limited evidence for emergency cerclage placement in twin gestations with cervical dilatation suggests a very significant improvement in regards to pregnancy prolongation and possibly neonatal survival. $., 13,14$

An interesting observation in our series is that none of the patients had a history of either a prior preterm birth nor a second-trimester loss. Only one patient had a gynecologic risk factor, and she delivered triplets at $32^{6} / 7$ weeks. This supports the finding of Goldenberg et al that in twin (and presumably all multifetal) gestations, "conventional" risk factors for SPTB in are not consistent predictors. ${ }^{3}$ This observation is also consistent with Pereira et al, who did not note any association with obstetric history and interval to delivery of SPTB $<28$ weeks. They hypothesized that cervical dilation prior to 26 weeks is almost uniformly abnormal, and that once the progression has reached that point, prior history does not influence outcome. ${ }^{15}$

In summary, our case series demonstrated that emergency cerclage placement in multifetal gestations with cervical dilatation and exposed fetal amniotic membranes resulted in a pregnancy prolongation of 60.25 days. Intervention in this uniquely high-risk population may be of benefit.

\section{References}

1 Martin JA, Hamilton BE, Sutton PD, et al. Births: final data for 2006. National Vital Statistics Reports 2009;57:1-102
2 Fox NS, Rebarber A, Roman AS, Klauser CK, Saltzman DH. Association between second-trimester cervical length and spontaneous preterm birth in twin pregnancies. J Ultrasound Med 2010;29: 1733-1739

3 Goldenberg RL, Iams JD, Miodovnik M, et al. The preterm prediction study: risk factors in twin gestations. Am J Obstet Gynecol 1996;175(4 Pt 1):1047-1053

4 Yang JH, Kuhlman K, Daly S, Berghella V. Prediction of preterm birth by second trimester cervical sonography in twin pregnancies. Ultrasound Obstet Gynecol 2000;15:288-291

5 Fox NS, Saltzman DH, Klauser CK, Peress D, Gutierrez CV, Rebarber A. Prediction of spontaneous preterm birth in asymptomatic twin pregnancies with the use of combined fetal fibronectin and cervical length. Am J Obstet Gynecol 2009;201:313, e1-e5

6 Ramin KD, Ogburn PL Jr, Mulholland TA, Breckle RJ, Ramsey PS. Ultrasonographic assessment of cervical length in triplet pregnancies. Am J Obstet Gynecol 1999;180(6 Pt 1):1442-1445

7 To MS, Skentou C, Cicero S, Liao AW, Nicolaides KH. Cervical length at 23 weeks in triplets: prediction of spontaneous preterm delivery. Ultrasound Obstet Gynecol 2000;16:515-518

8 Berghella V, Rafael TJ, Szychowski JM, Rust OA, Owen J. Cerclage for short cervix on ultrasonography in women with singleton gestations and previous preterm birth: a meta-analysis. Obstet Gynecol 2011;117:663-671

9 Althuisius SM, Dekker GA, Hummel P, Bekedam DJ, van Geijn HP. Final results of the Cervical Incompetence Prevention Randomized Cerclage Trial (CIPRACT): therapeutic cerclage with bed rest versus bed rest alone. Am J Obstet Gynecol 2001;185:1106-1112

10 Newman RB, Krombach RS, Myers MC, McGee DL. Effect of cerclage on obstetrical outcome in twin gestations with a shortened cervical length. Am J Obstet Gynecol 2002;186:634-640

11 Roman AS, Rebarber A, Pereira L, Sfakianaki AK, Mulholland J, Berghella $\mathrm{V}$. The efficacy of sonographically indicated cerclage in multiple gestations. J Ultrasound Med 2005;24:763-768; quiz 770-771

12 Berghella V, Odibo AO, To MS, Rust OA, Althuisius SM. Cerclage for short cervix on ultrasonography: meta-analysis of trials using individual patient-level data. Obstet Gynecol 2005;106:181-189

13 Althuisius SM, Dekker GA, Hummel P, van Geijn HP; Cervical incompetence prevention randomized cerclage trial. Cervical incompetence prevention randomized cerclage trial: emergency cerclage with bed rest versus bed rest alone. Am J Obstet Gynecol 2003;189:907-910

14 Gupta M, Emary K, Impey L. Emergency cervical cerclage: predictors of success. J Matern Fetal Neonatal Med 2010;23:670-674

15 Pereira L, Cotter A, Gómez R, et al. Expectant management compared with physical examination-indicated cerclage (EMPEC) in selected women with a dilated cervix at 14(0/7)-25(6/7) weeks: results from the EM-PEC international cohort study. Am J Obstet Gynecol 2007;197:483, e1-e8

16 Stupin JH, David M, Siedentopf JP, Dudenhausen JW. Emergency cerclage versus bed rest for amniotic sac prolapse before 27 gestational weeks. A retrospective, comparative study of 161 women. Eur J Obstet Gynecol Reprod Biol 2008;139:32-37

17 Ventolini G, Genrich TJ, Roth J, Neiger R. Pregnancy outcome after placement of "rescue" Shirodkar cerclage. J Perinatol 2009;29: 276-279

18 Daskalakis G, Papantoniou N, Mesogitis S, Antsaklis A. Management of cervical insufficiency and bulging fetal membranes. Obstet Gynecol 2006;107(2 Pt 1):221-226 